\title{
Article \\ OsCBE1, a Substrate Receptor of Cullin4-Based E3 Ubiquitin Ligase, Functions as a Regulator of Abiotic Stress Response and Productivity in Rice
}

\author{
Juyoung Choi ${ }^{1} \mathbb{D}$, Wonkyung Lee ${ }^{1}$, Gynheung An ${ }^{2}$ and Seong-Ryong Kim ${ }^{1, *}$ \\ 1 Department of Life Science, Sogang University, Seoul 04107, Korea; cjy1835@naver.com (J.C.); \\ wk971018@naver.com (W.L.) \\ 2 Department of Plant Molecular Systems Biotechnology, Kyung Hee University, Yongin 17104, Korea; \\ genean@khu.ac.kr \\ * Correspondence: sungkim@sogang.ac.kr
}

Citation: Choi, J.; Lee, W.; An, G.; Kim, S.-R. OsCBE1, a Substrate Receptor of Cullin4-Based E3 Ubiquitin Ligase, Functions as a Regulator of Abiotic Stress Response and Productivity in Rice. Int. J. Mol. Sci. 2021, 22, 2487. https://doi.org/ $10.3390 /$ ijms 22052487

Academic Editor: Soulaiman Sakr

Received: 21 January 2021

Accepted: 24 February 2021

Published: 2 March 2021

Publisher's Note: MDPI stays neutral with regard to jurisdictional claims in published maps and institutional affiliations.

Copyright: (c) 2021 by the authors. Licensee MDPI, Basel, Switzerland. This article is an open access article distributed under the terms and conditions of the Creative Commons Attribution (CC BY) license (https:/ / creativecommons.org/licenses/by/ $4.0 /)$.

\begin{abstract}
Ubiquitination is an important environmental stress response, and E3 ubiquitin ligases play a major role in the process. T-DNA insertion mutants of rice, Oscbe1-1, and Oscbe1-2, were identified through the screening of cold stress tolerance at seedling stage. Oscbe1 mutants showed a significantly higher cold stress tolerance in the fresh weight, chlorophyll content, and photosynthetic efficiency than wild type. Molecular prediction showed that OsCBE1 (Oryza sativa Cullin4-Based E3 ubiquitin ligase1) encoded a novel substrate receptor of Cullin4-based E3 ubiquitin ligase complex (C4E3). Whereas Oscbe1 mutants had fewer panicles and grains than wild type in the paddy field, the overexpression lines of OsCBE1 had more panicles and grains, suggesting that OsCBE1 is involved in the regulation of both abiotic stress response and development. Oscbe1 mutants also showed ABA hypersensitivity during seed germination, suggesting OsCBE1 function for the stress response via ABA signaling. In silico analysis of OsCBE1 activity predicted a CCCH-type transcription factor, OsC3H32, as a putative substrate. Co-IP (Co-immunoprecipitation) study showed that OsCBE1 interacts with OsDDB1, an expected binding component of OsCBE1 and OsC3H32. Additionally, expression of OsOLE16, OsOLE18, and OsBURP5 were negatively related with expression of OsCBE1. These results suggest that $O S C B E 1$ functions as a regulator of the abiotic stress response via $\mathrm{CCCH}$ as a member of the C4E3.
\end{abstract}

Keywords: abiotic stress; cullin4; crop productivity; E3 ubiquitin ligase; rice

\section{Introduction}

Since plants are sessile, it is hard for a plant to escape from continually changing environments. These external conditions are often unfavorable and the environmental conditions strictly limit geographical distribution of plants and productivity in agriculture [1]. The productivity of crops decreases more than 50\% from abiotic stress [2], and global climate change is threatening plant habitats [3]. Therefore, the understanding of the abiotic stress response of plants is necessary to meet the global food demand under global climate change.

In stress condition, there are various changes in plants, such as gene expressions and metabolite composition [4]. To make these changes, the stress sensing-signaling process is required, and a few putative stress sensors such as OSCA1 [5] and COLD1 [6] have been reported. In the stress signaling, phytohormone abscisic acid (ABA) is one of the most important signaling molecules. Binding of ABA to PYR/PYL/RCAR families [7] and PP2Cs [8] evokes signaling cascades regulating PP2Cs [8] and SnRKs [9]. Then, at the end of the signaling cascades, various transcription factors of the bZIP [10], MYB/MYC [11], CBF/DREB [12], and NAC [13] families regulate expression of stress-responsive genes. Some CBF/DREB $[14,15]$ and MYB [16] family members are regulated by ABA-independent 
signaling pathway. Consequently, physiological and molecular changes occur to adapt and survive in harsh conditions.

Post-translational modifications of proteins, such as phosphorylation and ubiquitination, have a vital role in the signal transduction of abiotic stress response as well [17]. Ubiquitination regulates various biological functions in plants. Ubiquitination occurs with three steps: 1. ATP dependent activation of ubiquitin by E1 ubiquitin-activating enzyme. 2. Transfer of ubiquitin to E2 ubiquitin-conjugating enzyme. 3. Transfer of ubiquitin to target and forming covalent bonds between lysin residues in ubiquitin and target by E3 ubiquitin ligase [18]. There are various kinds of ubiquitination, including mono- or polyubiquitination, and each ubiquitination may cause different kinds of regulation, such as protein degradation by $26 \mathrm{~S}$ proteasome, activation, and localization [19].

In the plant species, rice has 1483 putative E3 ubiquitin ligase genes (4.3\% of proteincoding genes in rice), and Arabidopsis has 1424 putative E3 ubiquitin ligase genes (5.4\% of protein-coding genes in Arabidopsis) [20-23]. Monomeric E3 ubiquitin ligases of HECT, U-box, and RING work alone [24]. Meanwhile, multimeric E3 ubiquitin ligases of SCF complex [25], APC/C- [26], cullin 3- [27], and cullin 4- [23], work with cullin or other components as complexes. Since the cullin 4-based E3 ubiquitin ligase complex (C4E3) was first reported in Arabidopsis [28], various functions of C4E3 have been elucidated, including regulation of photomorphogenesis [28], embryogenesis [29], flowering [30], immunity [31], and stress signaling [32]. The C4E3 consists of cullin 4, RBX1, DDB1, and a substrate receptor named DCAF (DDB1 Cullin4 Associated Factor) [33]. DCAFs commonly have a conserved 16-17 amino acid motif called DWD box (DDB1 binding WD40), which gives a binding site for DDB1 [29]. DCAFs containing only WDxR motifs, which are 13-16th residues of the DWD box, have also been reported as non-DWD DCAFs, where WDxR is crucial for the binding of the DCAFs to DDB1 [34]. It has been estimated that there are 151 and 119 DCAFs in rice and Arabidopsis, respectively [22,23], although most of them remain to be characterized.

In this study, we studied an abiotic stress tolerant mutant, Oscbe1, and characterized it at the molecular level. OsCBE1, a putative novel DCAF protein, was further characterized for its physiological role in the regulation of abiotic stress tolerance and crop productivity. Furthermore, an in silico identification of OsCBE1 substrate, OsC3H32, was further characterized in detail.

\section{Results}

\subsection{Identification of Cold Stress Mutant Oscbe1}

To investigate the function of $\mathrm{E} 3$ ubiquitin ligase on the abiotic stress response, we have screened a mixed pool of transgenic rice with T-DNA tagged mutation of putative E3 ubiquitin ligase genes for the cold stress tolerance. A cold tolerant mutant Oscbe1-1 (PFG_4A-50680) was identified (Figure 1a), and the T-DNA tagging loci (LOC_Os01g09020) was confirmed by inverse PCR. The corresponding gene was named Oryza sativa Cullin4Based E3 ubiquitin ligase1 (OsCBE1). An allelic mutant line (Oscbe1-2, PFG_4A-01910) of Oscbe1-1 was identified from RiceGE (http://signal.salk.edu/cgi-bin/RiceGE), and the T-DNA insertion loci was confirmed on the $3^{\prime}$-UTR of CBE1 (Figure 1b). From the T2 generation of both Oscbe1 mutants, homozygote T-DNA tagging mutants were identified by genotyping, as shown in Figure 1c, and were confirmed via checking the expression of OsCBE1 (Figure 1d). In addition, OsCBE1 overexpression (Ox) lines were made to study the function of the gene. Of several Ox lines obtained, Ox8 and Ox15 were selected and further examined with the Oscbe1 mutants. As shown in Figure 1d, OsCBE1 Ox8 and Ox15 showed 1.23 and 5.55 times stronger expression of OsCBE1, compared to the wild type, respectively. The expression of the OsCBE1 gene during development was examined in various tissues by RT-PCR. As shown in Figure 1e, OsCBE1 was highly expressed in the callus and mature leaves, but barely detected in the seedlings. OsCBE1 contains $1539 \mathrm{bp}$ of the open reading frame and encodes 512 amino acid-long polypeptides. Using the NCBI conserved domain search tool [35], seven WD repeat domains were found in the OsCBE1. 
These domains were predicted to have a seven bladed $\beta$-sheet propeller-like structure (Figure 1f) using Robetta server [36]. Even though DWD box was not detected in OsCBE1, one of the seven WD domains of OsCBE1 at the position of amino acid 360 showed a WDxR motif (Figure 1g). These indicate that OsCBE1 has conserved sequences of DCAF and may work as a non-DWD DCAF, where WDxR is crucial for the binding of the DCAF to DDB1.

a.

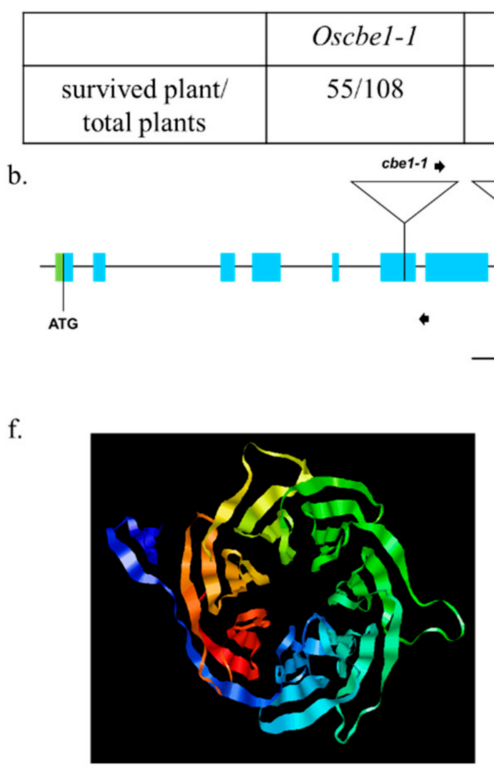
c. d.

Oscbe1-1 Oscbe1-2 OsCBE1 OsCBE1 WT

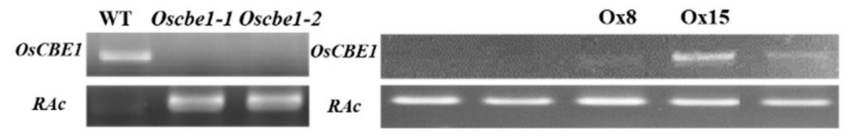

e.

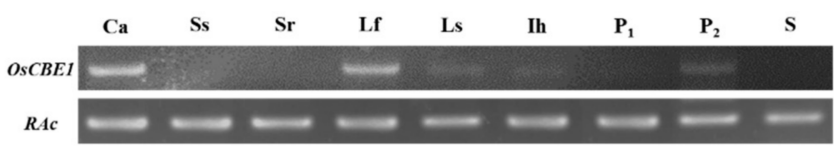

$1 \mathrm{~Kb}$

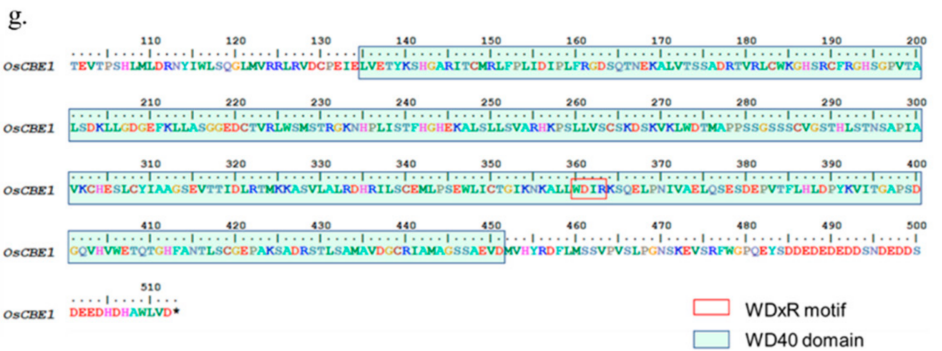

Figure 1. Screening of Cold tolerant E3 ubiquitin ligase line. (a) Survival rates of 7d rice seedlings after low temperature treatment. (b) Map depicting the tagging position of two allelic T-DNA insertion mutant lines of OsCBE1. Exons (blue boxes), 5'UTR (green box), 3'UTR (pink box), and introns (lines) are indicated. (c) Identification of Oscbe1 T-DNA insertion mutants (d) Expression profile of OsCBE1 in mutant and overexpression lines. (e) Expression profile of OsCBE1 in different tissues of rice. Ca, callus; Ss, shoots at 7 days after germination (DAG); Sr, roots at 7 DAG; Lf, mature leaves; Ls, flag leaf sheaths; Ih, the highest internode at pre-heading stage; P1, 1-2 cm panicles; P2, 3-8 cm panicles. (f) Predicted seven bladed beta propeller structure of WD domains in OsCBE1 protein. Image colored by rainbow N-to C-terminus. (g) WD domain of OsCBE1 with WDxR motif.

\subsection{OsCBE1 Negatively Regulates Stress Response and ABA Signaling}

To investigate the role of OsCBE1 in abiotic stress, various stress tolerance of Oscbe1 mutants with Ox lines were estimated as survival rates after the recovery from the stress of salt, drought, and cold. For salt stress, the survival rates of both Oscbe1-1 and Oscbe1-2 were more than $40 \%$, whereas the rate was $12.3 \%, 11.5 \%$, and $5.5 \%$ for the wild type, OsCBE1 Ox8 (1.23 times overexpressed than wildtype), and OsCBE1 Ox15 (5.55 times overexpressed than wildtype), respectively (Figure 2a). For drought stress, more than $35 \%$ of both Oscbe1-1 and Oscbe1-2 seedlings survived, whereas the rate was $18.3 \%, 18.3 \%$, and $10.9 \%$ for the wild type, Ox8, and Ox15, respectively (Figure 2b). For cold stress, the survival rates of both Oscbe1-1 and Oscbe1-2 were more than 50\%, whereas those of the wild type and Ox lines were less than $30 \%$ (Figure 2c). For the tested abiotic stresses, both Oscbe1-1 and Oscbe1-2 showed significantly higher survival rate than that of the wild type, as estimated by Chi-square analysis with $p<0.05$. Whereas OsCBE1 Ox8 showed similar survival rate to wild type, the OsCBE1 Ox15 line showed significantly lower survival rate to salt stress and slightly lower survival rate to cold and drought stress. During the cold stress treatment up to four days, $\mathrm{Fv} / \mathrm{Fm}$, an indicator of the quantum yield of photosystem II, was rather slowly decreased in Oscbe1 mutants, compared to either wild type or OsCBE1 Ox lines. While Fv /Fm of Oscbe1-1 and Oscbe1-2 were 0.35 and 0.34 , respectively, the value of OsCBE1 Ox15 declined to 0.17 after four days of cold treatment (Figure 2d). After seven 
days of recovery from the cold stress treatment, the chlorophyll contents of both Oscbe1 mutants were about $4.21 \pm 1.21 \mathrm{mg} / \mathrm{g}$ of fresh weight $(\mathrm{FW})$, which was higher than that of the wild type (1.0 mg/g FW). OsCBE1 Ox15 had a much lower chlorophyll content of $0.23 \pm 0.07 \mathrm{mg} / \mathrm{g} \mathrm{FW}$, although, OsCBE1 Ox8 had similar chlorophyll content to the wild type (Figure 2e). Regarding salt stress of $250 \mathrm{mM} \mathrm{NaCl}$ for $84 \mathrm{~h}$, the average FW of Oscbe1-1 after seven days of recovery was $139.1 \pm 8.6 \mathrm{mg}$. Meanwhile, the value of the wild type was $77.4 \pm 5.1 \mathrm{mg}$ (Figure 2f). These physiological changes after abiotic stress treatment suggest that OsCBE1 work as a negative regulator of abiotic stress tolerance.

a.

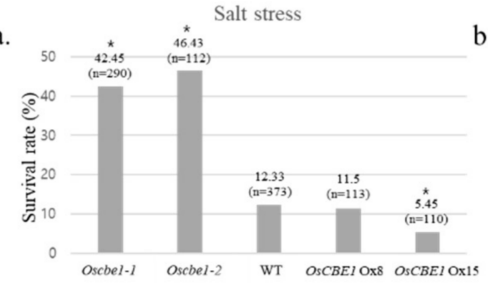

d.

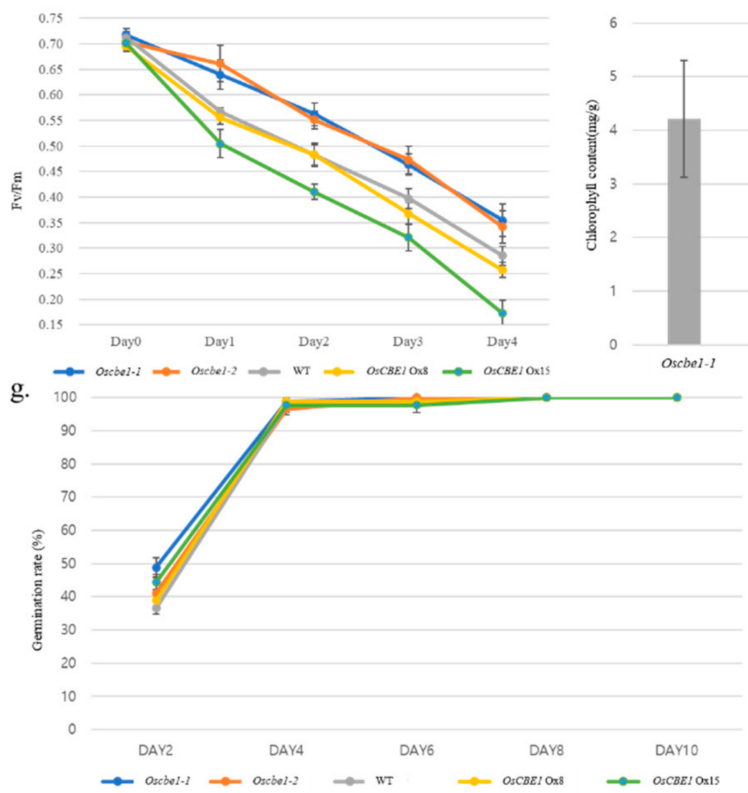

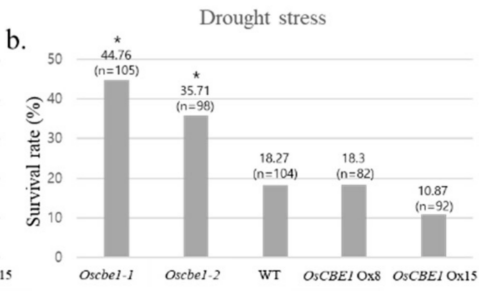

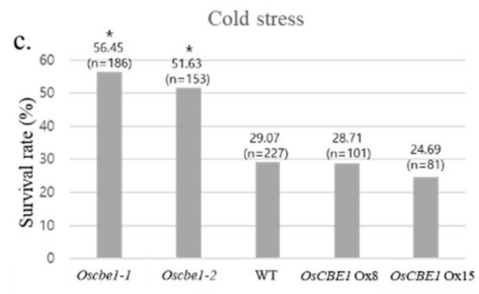

f.
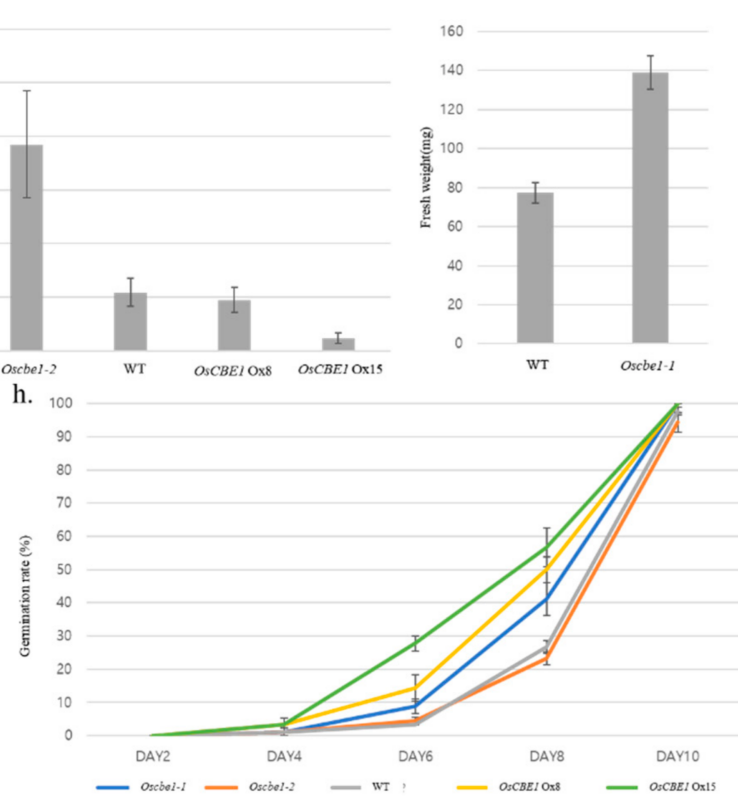

Figure 2. Phylogenetic traits of $C B E 1$ lines. Abiotic stress tolerance was analyzed with survival rate in OsCBE1 lines. Before stress treatment, each plant was grown in soil for seven days. (a) Salt stress was treated for $84 \mathrm{~h}$ by irrigating with $250 \mathrm{mM} \mathrm{NaCl}$ solution. Survival rate was analyzed, after 7 days of recovery. (b) Drought stress treatment for $36 \mathrm{~h}$ by withholding water. Survival rate was analyzed after seven days of recovery. (c) Cold stress treatment for $96 \mathrm{~h}$ under $4{ }^{\circ} \mathrm{C}$ and $130 \mu \mathrm{Mm}^{-2} \mathrm{~s}^{-1}$ light intensity. Survival rate was analyzed after seven days of recovery. (d) Decrease of chlorophyll florescence (Fv/Fm) of OsCBE1 lines during cold stress in $4^{\circ} \mathrm{C}$ and $130 \mu \mathrm{Mm}^{-2} \mathrm{~s}^{-1}$ light intensity was analyzed. (e) Chlorophyll contents of OsCBE1 lines after cold stress in $4{ }^{\circ} \mathrm{C}$ and $130 \mu \mathrm{Mm}^{-2} \mathrm{~s}^{-1}$ light intensity for four days were analyzed. (f) Fresh weights of OsCBE1 lines after salt stress in $250 \mathrm{mM} \mathrm{NaCl}$ treatment for $84 \mathrm{~h}$ were analyzed. (g) Germination rate of transgenic lines of $O s C B E 1$ were analyzed in a $\frac{1}{2} \mathrm{MS}, 27^{\circ} \mathrm{C}$, dark condition after $50 \%$ bleach treatment for $40 \mathrm{~min}$. (h) Germination rate of transgenic lines of OsCBE1 were analyzed in $\frac{1}{2} \mathrm{MS}, 5 \mu \mathrm{M} A B A, 27^{\circ} \mathrm{C}$, dark condition after $50 \%$ bleach treatment for $40 \mathrm{~min} .{ }^{*}$, significant difference from wild type (Chi-square test with $p<0.05$ ); Error bar, \pm Standard error.

In addition, leaf disc assay was performed to analyze salt stress and cold stress tolerance of mature plants $(\approx 60 \mathrm{DAG})$. Leaf disk assay, under various concentrations of $\mathrm{NaCl}$, revealed that more chlorophyll remained in leaf discs of Oscbe1-1 and Oscbe1-2 than in the wild type (WT) plants (Figure S1a-c). After five days of salt stress treatment, the chlorophyll contents in leaf discs in Oscbe1-1 and Oscbe1-2 were about $4.8 \pm 1.12 \mathrm{mg} / \mathrm{g}$ of FW and $1.06 \pm 0.256 \mathrm{mg} / \mathrm{g}$ of FW, which were higher than that of the wild type 
$(0.9 \pm 0.093 \mathrm{mg} / \mathrm{g} \mathrm{FW})$. Leaf discs of OsCBE1 Ox15 had a much lower chlorophyll content of $0.36 \pm 0.123 \mathrm{mg} / \mathrm{g}$ FW (Figure S1c). Additionally, Fv / Fm slowly decreased in leaf disks of Oscbe1 mutants, compared to leaf disks of the wild type or OsCBE1 Ox lines. After five days of floating on autoclaved water at $4{ }^{\circ} \mathrm{C}, \mathrm{Fv} / \mathrm{Fm}$ of leaf discs of Oscbe1-1 and Oscbe1-2 were 0.42 and 0.372 , respectively. However, leaf discs of wild type and OsCBE1 Ox8 had lower Fv /Fm of 0.195 and 0.190, respectively. Additionally, leaf discs of OsCBE1 Ox15 had a much lower Fv/Fm of 0.097 (Figure S1d).

To analyze whether OsCBE1 was related to the ABA signaling pathway, we germinated seeds of Oscbe1 mutants and Ox lines in agar media containing ABA. In the media without $\mathrm{ABA}$, germination rate was similar between the wild type and OsCBE1 lines (Figure 2g). In the media with $5 \mu \mathrm{M} \mathrm{ABA}$, germination delay was different in each line. Whereas Oscbe1 mutants showed hypersensitivity to ABA during germination, the Ox lines showed slightly enhanced germination compared to either the wild type or Oscbe1 mutants (Figure 2h).

\subsection{Expression of OsCBE1 Positively Related to Crop Productivity}

The knockout mutants, Oscbe1-1 and Oscbe1-2, and the overexpression line Ox15 were grown in a paddy field in the normal growth condition. Culm length were similar between those mutants and the wild type (Figure 3a). However, Oscbe1 mutants had less tillers than wild type and Ox15. The number of tillers per plant were 9-12 from Oscbe1 mutants, versus 15 from wild type and Ox15 (Figure 3b,g). Whereas the number of filled grains per panicle from Oscbe 1 mutants were 10-20\% less than those from wild type, Ox15 had over $40 \%$ more filled grains per panicle than wild type (Figure 3c,f). Similarly, compared to wild type, the length of panicles was $\approx 10 \%$ shorter in Oscbe 1 mutants and $\approx 30 \%$ longer in Ox15 (Figure 3d,f). Therefore, the grain yield per plant of Oscbe1 mutants and Ox15 were 34-38\% less and $45 \%$ more, respectively, than that of the wild type. (Figure 3e,g). Taken together, the expression of $O S C B E 1$ shows a positive relation to agronomical productivity in rice.

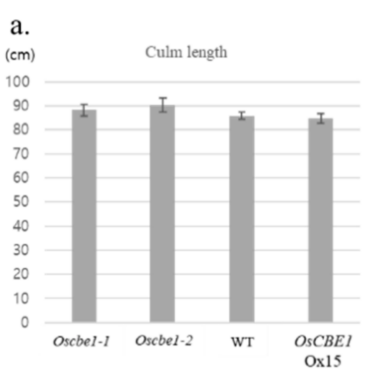

e.

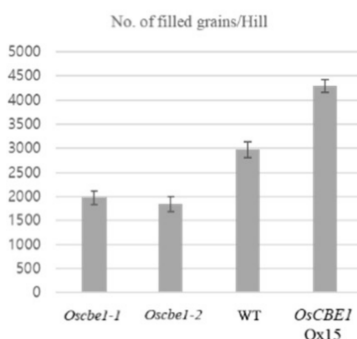

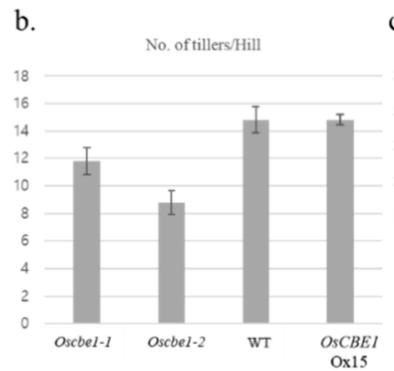

g.

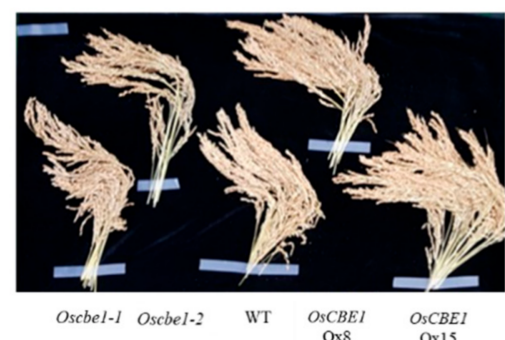

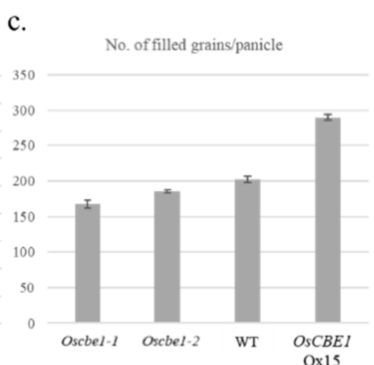

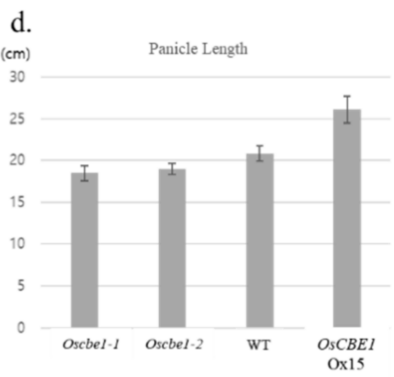

f.

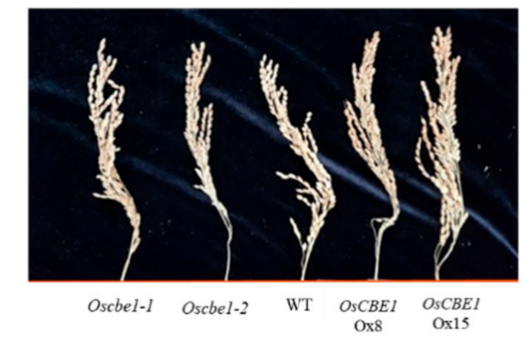

Figure 3. Agronomical traits of CBE1 lines. (a-e) Agronomical traits of OsCBE1 lines are presented. (a) Culm length; (b) Number of tillers per hill; (c) Number of filled grains per panicle; (d) Panicle Length; (e) Number of filled grains per hill. Each of the results are presented as means \pm standard error. (f) Panicles from a single OsCBE1 line plant are presented. (g) Single panicle of each OsCBE1 line are presented.

\subsection{Functional Role of OsCBE1 and In Silico Identification of the OsCBE1 Binding Partners}

Since OsCBE1 has conserved sequences of substrate receptor of $C 4 \mathrm{E} 3$, putative interaction partner of OsCBE1 was examined in silico with biological evidence and protein 
docking simulation. From the STRING database [37], five candidate genes were identified based on co-expression, co-occurrence, and evidence of biological relation between genes (Figure S2, Table S1), although there was no experimental evidence. Therefore, interaction modeling with OsCBE1 was performed using both Phyre2.0 server and ROSIE server docking2 protocol for further analysis [38,39]. The energy distribution analysis from the docking simulation with only one candidate, $\mathrm{OsC} 3 \mathrm{H} 32$, showed a funnel-shaped distribution (Figure 4a-e). Since DCAFs in C4E3 interact with both substrate and DDB1, the structure of the $\mathrm{C} 4 \mathrm{E} 3$ complex was predicted in silico as well. The predicted structure of OsCBE1 looks like a "ladle" with a "bowl" composed of a seven-bladed $\beta$-propeller and "handle" composed of several $\alpha$-helixes. A simulated complex with the lowest energy showed that OsC3H32 binds to the "handle" of OsCBE1. Since the WDxR motif is placed in the "bowl" of OsCBE1, the predicted complex, OsDDB1-OsCBE1-OsC3H32, formed without conformational hindrance (Figure $4 \mathrm{f}$ ). Therefore, OsC3H32 was selected as a putative substrate of OsCBE1 and further characterized.
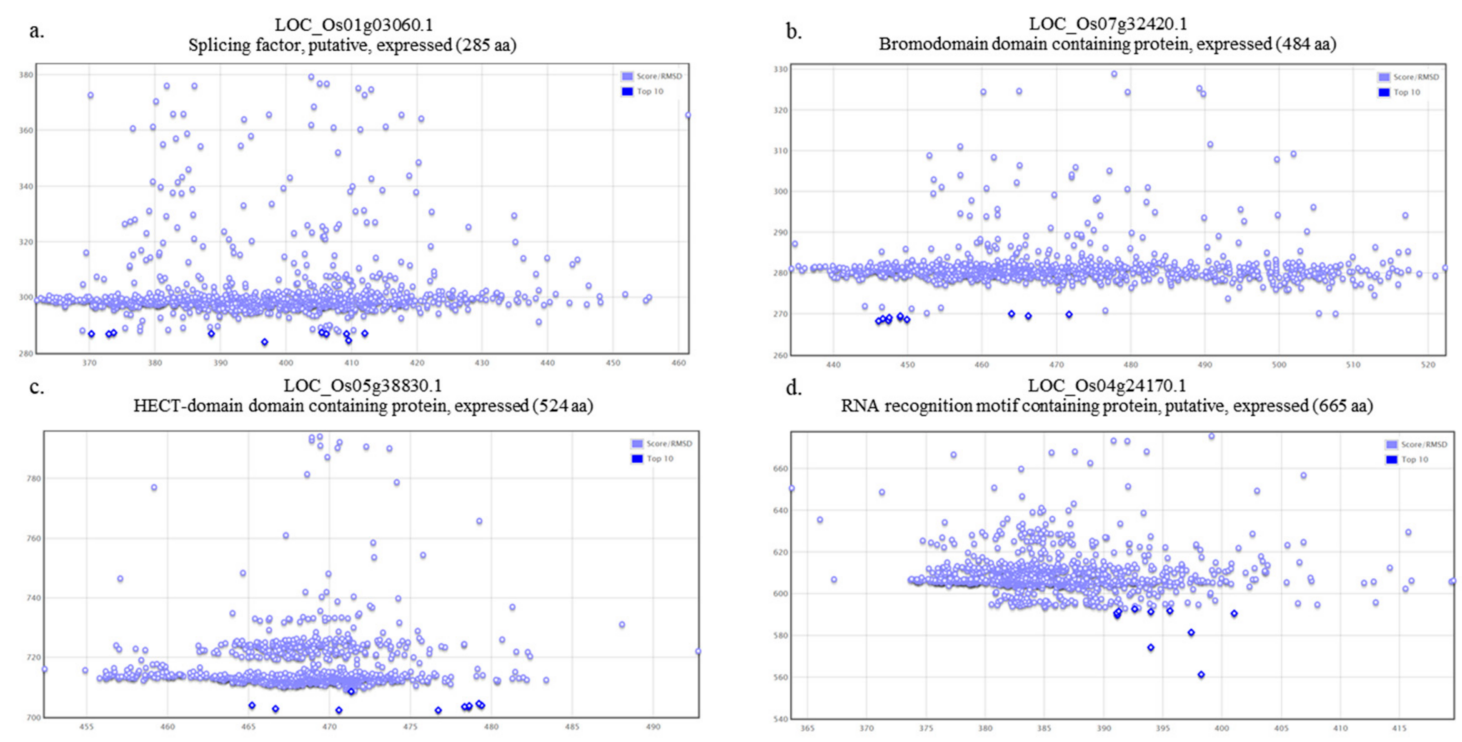

e. $\quad$ LOC Os 04957600.1 Zinc finger C-x8-C-x5-C-x3- $\mathrm{H}$ type family protein, expressed (711 aa)

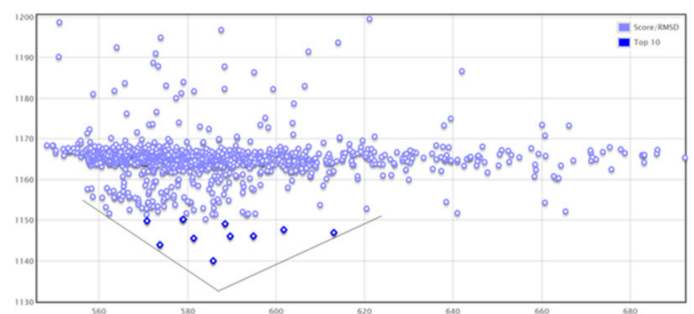

f.

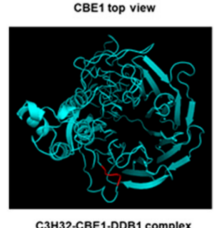

CBE1 side view

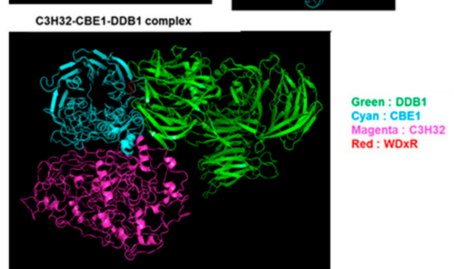

Figure 4. In silico identification of the OsCBE1 binding partners. (a-e) Energy plot of interaction energy between OsCBE1 and five putative substrates, LOC_Os01g03060.1 (a), LOC_Os07g32420.1 (b), LOC_Os05g38830.1 (c), LOC_Os04g24170.1 (d), and LOC_Os04g57600.1 (e), and Root-mean-square deviation of atomic positions (RMSD). Energy diagram of LOC_Os01g03060.1, LOC_Os07g32420.1, and LOC_Os05g38830.1 have horizontal distribution. Energy diagram of LOC_Os04g24170.1 has three downward plots, but most of the distribution is horizontal. Only the energy diagram of LOC_Os04g57600.1 shows funnel-like distribution (marked with black lines). (f) Predicted structure of OsCBE1 and OsDDB1-OsCBE1-OsC3H32 complex. 


\subsection{Physical Interaction of OsCBE1 with OsDDB1 and OsC3H32}

In order to examine whether OsCBE1 was a substrate receptor of $\mathrm{C} 4 \mathrm{E} 3$, the binding of OsCBE1 with OsDDB1 was examined. Both expression vectors of Myc-tagged OsCBE1 and HA-tagged OsDDB1 were constructed using pGA3817 and pGA3818, respectively. The vectors were co-transformed by electroporation into rice protoplasts prepared from the suspension cells of Dongjin wild type. Protein extracts from the transformed cells were used for Co-IP (Co-immunoprecipitation) analysis (See Materials and Methods). As shown in Figure 5, the OsDDB1 of $120 \mathrm{kD}$ was immunoprecipitated with the $61 \mathrm{kD}$ OsCBE1. However, the HA tag, negative control, was not immunoprecipitated with the OsCBE1 (Figure S3). We further examined whether OsCBE1 interacted with OsC3H32, the in silico predicted substrate in this study. An expression vector of HA-tagged $\mathrm{OsC} 3 \mathrm{H} 32$ was constructed using pGA3818 and then co-transformed into rice protoplast with the Myc-tagged OsCBE1 vector. The OsC3H32 of $77 \mathrm{kD}$ was also immunoprecipitated with the OsCBE1 (Figure 5), indicating that OsC3H32 could be a substrate of OsCBE1.

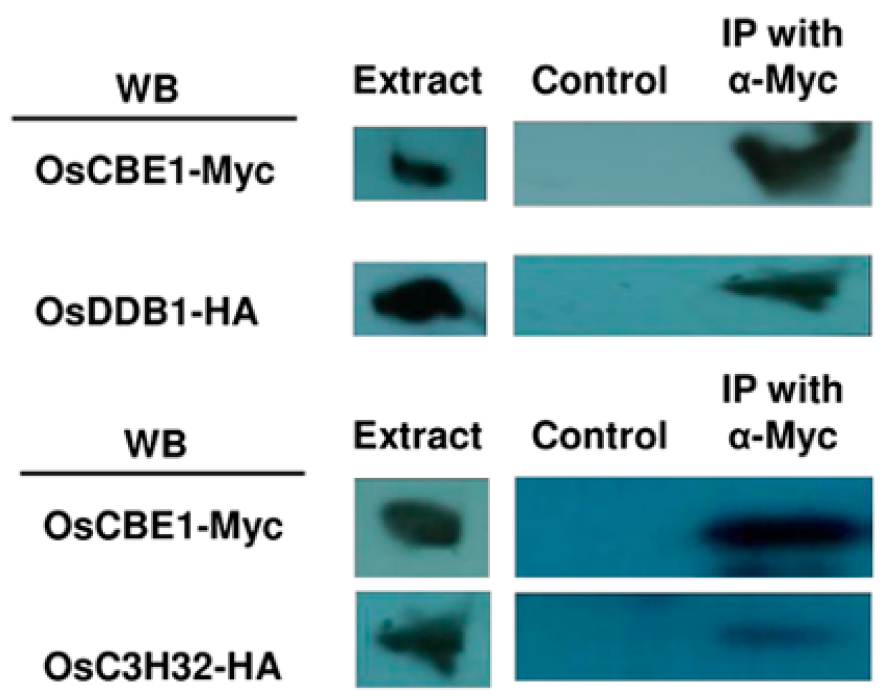

Figure 5. Co-IP with OsCBE1 and predicted substrate. To confirm whether the putative substrate from the in silico method can interact with OsCBE1, we performed Co-IP using transient expressed Myc tagged OsCBE1 and HA tagged predicted substrate in rice suspension cell.

\subsection{Oleosin Genes and an ABA Responsive Gene Are Negatively Regulated by OsCBE1}

Based on the fact that $\mathrm{OsC} 3 \mathrm{H} 32$ could be a substrate of OsCBE1, the function of the $\mathrm{OsC} 3 \mathrm{H} 32$ was studied in the literature. Since the function of $\mathrm{OsC} 3 \mathrm{H} 32$ has not been reported, an Arabidopsis homologue was searched using BLAST. It was reported that AtC3H17 is a homologue of OsC3H32 with an amino acid identity of 35.4\% [40]. AtC3H17 was reported to upregulate oleosin genes, AtOLEO1 and AtOLEO2, which had a pleiotropic function in development [41] and salt stress tolerance via ABA signaling pathway [40]. Therefore, the corresponding homologues of AtOLEO1 and AtOLEO2 were found in rice first. OsOLE16 and OsOLE18 were obtained as homologues of AtOLEO1 and AtOLEO2, respectively. Then, the expression of OsOLE16 and OsOLE18 were analyzed in the Oscbe1 and OsCBE1-Ox lines by qRT-PCR. As shown in Figure 6a, whereas the expression of OsOLE16 and OsOLE18 were increased in Oscbe1-1, the expression of OsOLE16 was decreased in OsCBE1-Ox15. The expression of OsOLE18 in the Ox line was similar to the wild type. We also examined the expression of OsBURP5, a rice homologue of the well-known ABA responsive gene AtRD22. The OsBURP5 mRNA was increased in Oscbe1 mutants, but barely detected in the Ox line, indicating OsCBE1 might positively regulate OsBURP5 in rice (Figure $6 b$ ). 
a.

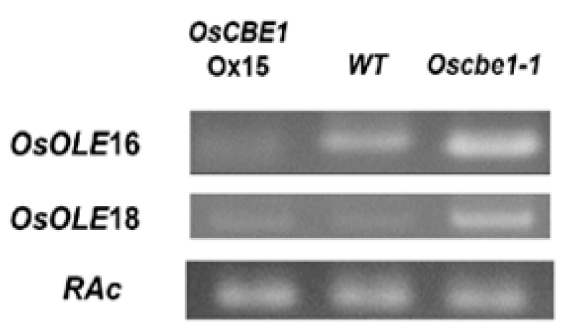

b.

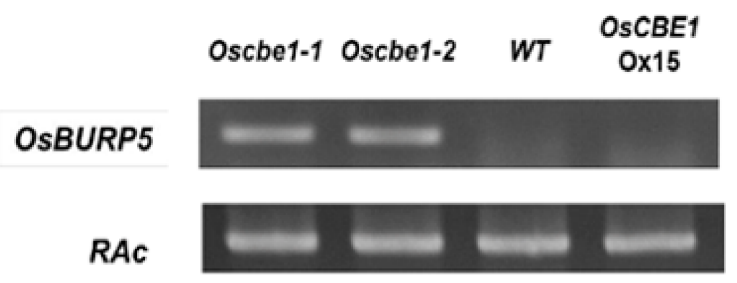

Figure 6. Regulation of OsOLE16, OsOLE18, and OsBURP5 in OsCBE1 lines. (a) Expression of OsOLE16 and OsOLE18 in OsCBE1 lines are presented. OsOLE16 and OsOLE18 are up-regulated in KO line. OsOLE16 are down-regulated in the overexpression line. (b) Expression of OsBURP5 in OsCBE1 lines are presented. OsBURP5 is upregulated in $\mathrm{KO}$ lines.

\section{Discussion}

In this study, we showed abiotic stress tolerance of Oscbe1 and the stress sensitivity of OsCBE1-Ox15, with various stress markers such as survival rates and chlorophyll fluorescence. $\mathrm{ABA}$ responses, germination delay, and $\mathrm{ABA}$ responsive gene expression were increased in Oscbe1 and were decreased in OsCBE1-Ox15, suggesting that OsCBE1 negatively regulates abiotic stress response through at least part of $\mathrm{ABA}$ pathway.

OsCBE1 belongs to non-DWD DCAFs, which was first shown in rice. It has been reported that DCAFs of ABD1 [42], ASG2 [43], DET1-DDA1 complex [44,45], DRS1 [46] DWA1, DWA2 [32], DWA3 [47], HOS15 [48], RAE1 [49], and WDR55 [50] regulate the ABA signaling pathway. With ABD1, OsCBE1 is another non-DWD type DCAF protein related to the ABA pathway. Recently, it was shown that a rice cullin4 gene, OsCUL4, was also induced by ABA, drought, and salt stress [51].

Most DCAFs, including OsCBE1, negatively regulates the ABA pathway, except DRS1 and WDR55 [46,50]. The functional regulation of DCAFs on the ABA pathway seems due to the character of C4E3. DDA1, the substrate receptor of C4E3, also negatively regulates the $\mathrm{ABA}$ pathway itself [52]. Whether the negative regulation on $\mathrm{ABA}$ pathway by DDA1 is related to the structural stabilization of C4E3 by interacting with DCAFs needs further studies. Similarly, most U-box E3 ubiquitin ligases negatively regulate the ABA pathway [53-60]. Contrary to C4E3, many RING-type E3 ubiquitin ligases positively regulate the ABA pathway $[56,60]$. Therefore, this bias of E3 ubiquitin ligases on ABA regulation pathway would be tuned and established during molecular evolution of this enzyme.

Photosynthetic efficiency is one of the major metabolic factors for increasing biomass. More than $90 \%$ of crop biomass is derived from photosynthetic products [61]. Although our Oscbe1 mutants showed overall abiotic stress tolerance (Figure 2), they showed a reduction in crop productivity in the normal paddy field (Figure 3). In many cases, rice production is limited by grain number $[62,63]$. Oscbe1 showed reduced tiller numbers and, therefore, reduced grain numbers compared to the wild type. It is remarkable that OsCBE1-Ox15 showed high yield increase compared to the wild type. OsCBE1-Ox15 showed increased production of agronomic traits, such as panicle length and grain numbers, than the wild type. We suggest that $O S C B E 1$ acts as a positive regulator for tiller formation and grain ripening. The stress tolerance and productivity were often reversed. Overexpression of OsPYL/RCAR5, an ABA receptor in rice, enhanced drought tolerance but severely reduced yields [64]. The knockout of the OsPYL family, which were drought sensitive, showed an increase in crop yield in normal conditions [65].

In this study, we found a substrate of OsCBE1 (Figures 4 and 5). One of the reasons that only a few E3 ubiquitin ligases were functionally characterized is the difficulty in finding their substrates. Many tools, including yeast-2-hybrid screening, mass spectrometry-based proteomics, substrate trapping proteomics, global protein stability profiling, protein microarray, phage display, and high-throughput quantitative microscopy, have been used and developed for decades [66-72]. However, these are laborious and time-consuming. 
Additionally, there are many hurdles to identify substrate: 1 . Too weak and short interactions between substrates and E3 ubiquitin ligases. 2. Delicate regulation of ubiquitination depends on various environments. 3. Rapid degradation and low cellular content of substrates [73]. These increase failure probability for finding out substrates and makes E3 ubiquitin ligase characterization difficult. In silico prediction tools, which are faster and less laborious, were successfully used in this study to find an interacting partner, OsC3H32, a $\mathrm{CCCH}$ family zinc finger protein. The in silico prediction was performed in three steps: 1. Interacting partner candidate sorted with biological evidences. 2. Protein docking simulation. 3. Docking funnel analysis and complex structure analysis. There are many available E3 ubiquitin ligases related OMICS database, including co-expression, co-occurrence, colocalization, protein interaction network and related phenotypes in transgenic lines, and E3 ubiquitin ligase-substrate interface database. In this study, five substrate candidates were sorted with co-expression and co-occurrence from the STRING database [37]. Recently, a new platform [74] which analyzes biological evidence by analyzing sequences and interactome databases was developed and would be helpful for sorting out substrate candidates. Co-IP data showed that OsCBE1 indeed binds to OsC3H32 in living rice cells (Figure 5). Although the function of $\mathrm{OsC} 3 \mathrm{H} 32$ has not been characterized in rice, an Arabidopsis ortholog, AtC3H17, increased the expression levels of oleosin genes, AtOLEO1 and AtOLEO2 [41]. The expression levels of OsOLE16 and OsOLE18 were also increased in the Oscbe1 mutants. Moreover, Seok et al. reported that expression level of the ABA responsive gene, $R D 22$ was increased by AtC3H17 [40]. We similarly confirmed that the expression of OsBURP5, a homologue of RD22, was increased in the Oscbe1 mutants (Figure 6). Furthermore, OsOLE16 and OsOLE18 are known as ABA responsive genes too [75]. These results suggest that OsCBE1 act as a positive regulator for oleosin synthesis, and a negative regulator for $\mathrm{ABA}$ signaling by inhibiting the function of OsC3H32 (Figure 7).

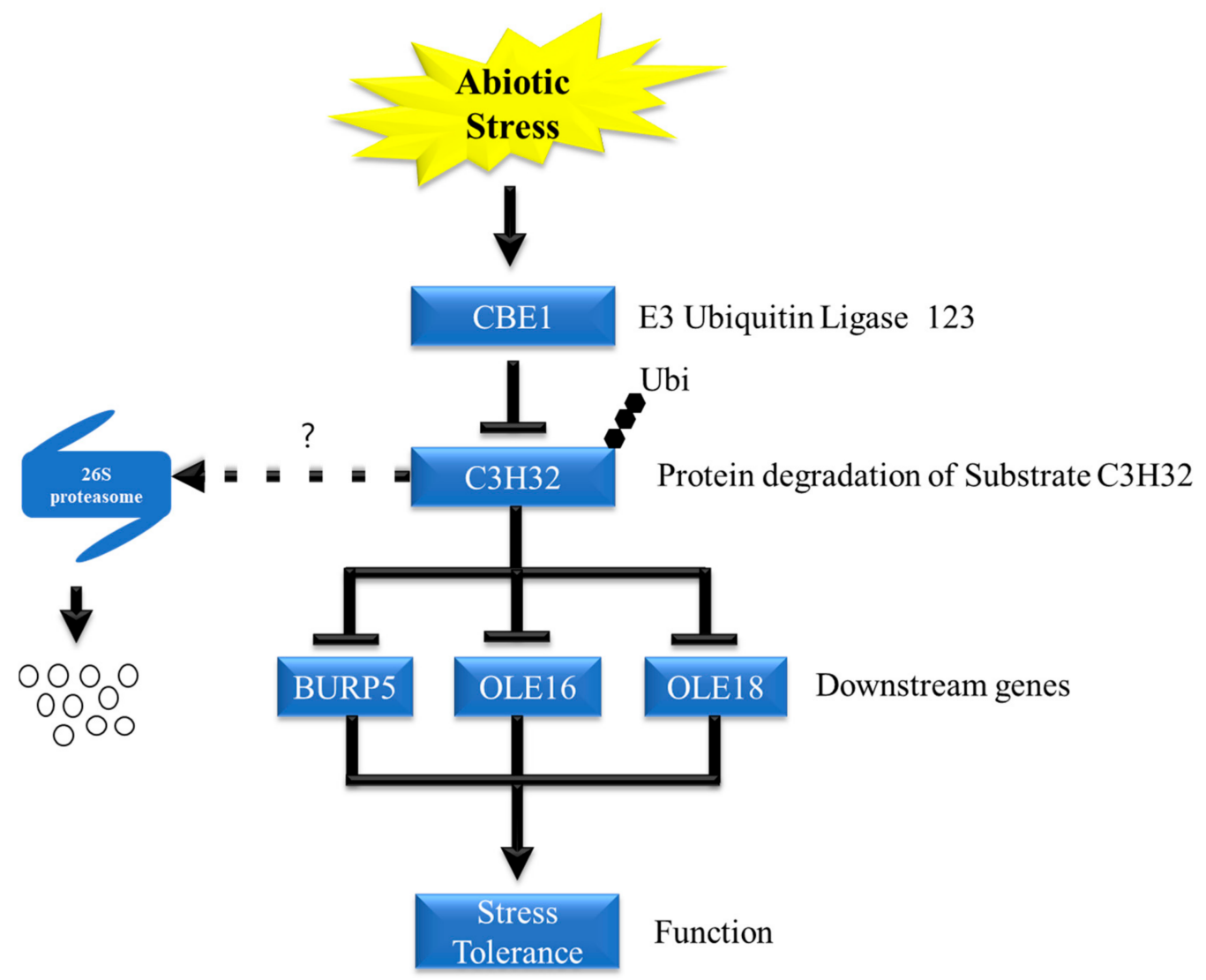

Figure 7. Model of OsCBE1 functioning in regulating abiotic stress response in rice. The arrow represents activation while the flat arrow represents inhibition. The dotted arrow and question mark represent hypothesis about how it works. 
Rice OsCBE1 is induced by abiotic stress and then ubiquitinates and may destabilize its substrate OsC3H32, by promoting its degradation through the $26 \mathrm{~S}$ proteasome. OsC3H32 are downregulated under abiotic stress, following which inhibition of downstream genes (OsBURP5, OsOLE16, and OsOLE18) were lifted which resulted in abiotic stress tolerance.

$\mathrm{CCCH}$ family zinc finger proteins are widely found in various eukaryotes [76-80]. In plants, many $\mathrm{CCCH}$ family transcription factors are related to ABA pathways [80-82]. In rice, OsC3H47 was highly induced by various stresses and ABA treatment, but the transcripts level of $\mathrm{OsC} 3 \mathrm{H} 32$ was not highly changed (less than twofold) in those stress conditions [83]. Therefore, it is suggested that OsC3H32 might be regulated at posttranslational level, and OsCBE1 would be a major regulator of OsC3H32.

\section{Materials and Methods}

\subsection{Plant Growth and Stress Tolerance Test}

Rice plants were grown as previously described with small modifications [84]. Briefly, rice seeds (Oryza sativa ssp. japonica cv. Dongjin) were sterilized in 0.05\% Spotak solution overnight at RT with rocking. Then, seeds were transferred to the sterilized wet paper tower and germinated in the dark at $28{ }^{\circ} \mathrm{C}$ for 2 days. Germinated seedlings were transferred to soil and cultured in a walk-in growth chamber (Koencon, Hanam, Korea) with $16 \mathrm{~h}$ of light $\left(28{ }^{\circ} \mathrm{C}, 70 \% \mathrm{RH}, 50 \mu \mathrm{mol} / \mathrm{m}^{2} \cdot \mathrm{s}\right.$ of light intensity) and $8 \mathrm{~h}$ of dark $\left(22{ }^{\circ} \mathrm{C}, 70 \% \mathrm{RH}\right)$.

For stress tolerance test for seedlings, cold, salt, and drought stress were treated as previously described with small modifications [84-86]. Briefly, seedlings 7 days after germination (DAG) were used. These were cold stress treated in a low-temperature chamber (Koencon, Hanam, Korea) with $16 \mathrm{~h}$ of daytime condition $\left(4^{\circ} \mathrm{C}, 60 \% \mathrm{RH}\right.$, and $50 \mu \mathrm{mol} / \mathrm{m}^{2} \cdot \mathrm{s}$ of light intensity) and $8 \mathrm{~h}$ of nighttime condition $\left(4^{\circ} \mathrm{C}, 60 \% \mathrm{RH}\right.$, and $0 \mu \mathrm{mol} / \mathrm{m}^{2} \cdot \mathrm{s}$ of light intensity); and salt stress treated in $250 \mathrm{mM}$ of $\mathrm{NaCl}$ solution. Both salt stress and drought stress were treated in a growth chamber under the same conditions as the growth condition. Survivor rate was analyzed after seven days of recovery in the growth chamber.

To examine stress tolerance of mature plants, a leaf disc assay was conducted as previously described with small modifications [84]. Fully expanded leaves of healthy mature plants $(\approx 60 \mathrm{DAG})$ were washed in deionized and autoclaved water. From these leaves, $\approx 8 \mathrm{~cm}$ diameter leaf disks were cut. For salt stress treatment, $100 \mathrm{mg}$ of leaf discs were floated for 6 days in a $10 \mathrm{~cm}$ diameter petri dish filled with a $30 \mathrm{~mL}$ solution of various concentrations of $\mathrm{NaCl}(0,250$, and $500 \mathrm{mM})$. For cold stress treatment, $100 \mathrm{mg}$ of leaf discs were floated in a $10 \mathrm{~cm}$ diameter petri dish filled with $30 \mathrm{~mL}$ of autoclaved water. Then, these were incubated for 5 days in a low-temperature chamber (Koencon, Hanam, Korea) with $16 \mathrm{~h}$ of daytime condition $\left(4{ }^{\circ} \mathrm{C}, 60 \% \mathrm{RH}\right.$, and $50 \mu \mathrm{mol} / \mathrm{m}^{2} \cdot \mathrm{s}$ of light intensity) and $8 \mathrm{~h}$ of nighttime condition $\left(4^{\circ} \mathrm{C}, 60 \% \mathrm{RH}\right.$, and $0 \mu \mathrm{mol} / \mathrm{m}^{2} \cdot \mathrm{s}$ of light intensity).

\subsection{Analysis of Chlorophyll Content and Fluorescence}

The third leaf from each cold treated rice seedling adapted in the dark for 40 min. After dark-adaptation, chlorophyll fluorescence was measured with a Plant Efficiency Analyzer (Hansatech, King's Lynn, UK). After stress treatment and 7 days of recovery, chlorophyll from each sample was extracted and quantified, as described previously [87].

\subsection{PCR and RT-PCR Analysis}

For genomic DNA extraction, $100 \mathrm{mg}$ of young leaves from the seedling were collected and ground in an MM300 Mixer Mill (Retsch, Haan, Germany). DNA was extracted using the method of Chen and Roland [88] and the genomic DNA was amplified by PCR, as described previously [89].

Total RNA was extracted using an RNA Plants Kit (Machery-Nagel, Düren, Germany) from $200 \mathrm{mg}$ of young leaves from the seedling collected. cDNA was synthesized from extracted RNA using TOPscript ${ }^{\mathrm{TM}}$ cDNA Synthesis Kit (Enzynomics, Daejeon, South Korea) and amplified for RT-PCR, as described previously [84]. Primer information for PCR and qRT-PCR analysis is in Table S2. Expression level of OsCBE1 was analyzed with ImageJ [90]. 


\subsection{Vector Construction}

To construct OsCBE1-overexpression vector, a full-length open reading frame of $\mathrm{Os}^{-}$ CBE1 was amplified from cDNA using Phusion High-Fidelity DNA Polymerase (Thermo Fisher Scientific, Waltham, MA, USA) with CBE1_Mlu1-F and CBE1_HindIII-R primer (Table S2). The amplified cDNA was introduced between the MluI and HindIII sites of pGA3436 binary vector under a maize ubiquitin promoter [91]. For the construction of Myc-tagged OsCBE1 expression vector, the full-length open reading frame of OsCBE1 amplified with CBE1_HindIII-F and CBE1_KpnI-R primer was inserted between the HindIII and KpnI sites of pGA3817 vector [92]. For the construction of HA-tagged OsDDB1 vector and HA-tagged OsC3H32 vector, each ORF amplified with their respective primer (Table S2) was inserted into pGA3818 [92].

\subsection{Generation of OsCBE1 Overexpression Lines}

OsCBE1 overexpression vector was transformed to calli of 'Dongjin' rice by Agrobacterium-mediated transformation methods, as described previously [84]. The transgenic plants were transferred to a paddy field in Kyung-Hee University (Suwon, Korea) for further growth.

\subsection{Germination Test}

To examine ABA sensitivity, rice seeds were germinated as described previously ${ }^{41}$ with small modifications [93]. Briefly, the 100 seeds per line were surface sterilized for 40 min and then transferred to $\frac{1}{2}$ MS media, supplemented with $5 \mu \mathrm{M} \mathrm{ABA}$, and germinated in the dark at $28^{\circ} \mathrm{C}$. Germinated seeds were counted every $12 \mathrm{~h}$.

\subsection{Evaluation of Agronomic Traits}

Rice plants were grown at the LMO paddy field of Kyung-Hee University, Suwon, South Korea (permission number: RDA-가A-2011-039) from May to October. Five plants from each line were evaluated for agronomic traits, including the numbers of tillers, panicles, filled grain per plant, and the number of filled grain per panicle. Additionally, we measured lengths of the panicles of each plant.

\subsection{In Silico Analysis}

Co-expression, co-occurance data, and substrate candidate were retrieved from the STRING database with low criteria option [37]. Protein structure was predicted using the PHYRE 2.0 server with intensive mode protocol [39]. In silico docking was performed using the ROSIE server with merged PDB file [38,94]. To interpret docking results, IRMS (Interface Root-Mean-Square Deviation) of the docked complex was calculated with dockQ, and interaction energy was calculated with Rosetta3 $[95,96]$. The OsDDB1-OsCBE1-OsC3H32 complex structure was predicted using ZDOCK, and the WDxR motif of was OsCBE1 set as a binding site between OsCBE1 and OsDDB1 [97]. Every protein structure in this paper was illustrated using PYMOL [98].

\subsection{Co-IP Analysis}

For protein interaction analysis, Myc-tagged OsCBE1 vector and HA-tagged OsDDB1 or $\mathrm{Os} \mathrm{C} 3 \mathrm{H} 32$ vector were co-transformed into rice calli using electroporation methods, as described previously [99]. After 16h from transfection, transfected cells were collected and Co-IP was performed, as described previously [100]. Briefly, $1 \mu \mathrm{L}$ of anti-Myc antibody (Cell Signaling, 9B11), $10 \mu \mathrm{L}$ protein A beads (Thermo Fisher Scientific, Waltham, Massachusetts, United States), and $10 \mu \mathrm{L}$ protein $\mathrm{G}$ beads (Thermo Fisher Scientific, Waltham, MA, USA) were mixed in $1 \mathrm{~mL}$ of binding buffer ( $50 \mathrm{mM}$ Tris-HCl, $75 \mathrm{mM} \mathrm{NaCl}, 5 \mathrm{mM}$ EDTA, $1 \mathrm{mM}$ DTT, $0.1 \mathrm{M}$ PMSF, and 1\% Triton X-100) for $3 \mathrm{~h}$ using a tube rotator. To extract total protein, transfected cells were incubated in the IP buffer (binding buffer with $1 \mathrm{X}$ protease inhibitor cocktail, Roche, Basel, Switzerland). The extracted protein mixtures were precleared with $10 \mu \mathrm{L}$ of protein $\mathrm{A} / \mathrm{G}$ beads mixture for $1 \mathrm{~h}$. Then, supernatant mixed with 
the anti-Myc antibody-bound protein A/G beads was incubated for $5 \mathrm{~h}$ on the tube rotator. Then, the beads were collected and washed, and the bound proteins were eluted in $20 \mu \mathrm{L}$ of IP buffer. After immunoprecipitation, a western blot was performed with horseradish peroxidase conjugated Myc-tag mouse mAb (9B11, Cell Signaling Technology, Beverly, MA, USA) and HRP conjugated HA-tag mouse mAb (6E2, Cell Signaling Technology, Beverly, MA, USA).

Supplementary Materials: Supplementary materials can be found at https:/ /www.mdpi.com/14 22-0067/22/5/2487/s1, Table S1: Information of primer sets for genotyping, vector construction and expression analysis, Table S2: Information of predicted substrates, selected by STRING score, Figure S1: Leaf disc assay of OsCBE1 lines under salt and cold stress, Figure S2: Co-expression and Co-ocurrence data between OsCBE1 and putative substrates, Figure S3: Negative control for OsCBE1 binding assay.

Author Contributions: Conceptualization, J.C. and S.-R.K.; methodology, J.C. and S.-R.K.; software, J.C.; validation, J.C.; formal analysis, J.C.; investigation, J.C., S.-C.L. and W.L.; resources, S.-C.L. and G.A.; data curation, J.C. and S.-R.K.; writing—original draft preparation, J.C.; writing-review and editing, J.C., W.L. and S.-R.K.; visualization, J.C.; supervision, G.A. and S.-R.K.; project administration, S.-R.K.; funding acquisition, S.-R.K. All authors have read and agreed to the published version of the manuscript.

Funding: This research was funded by the Next-Generation BioGreen 21 Program (PJ013295), Rural Development Administration, and the National Research Foundation (No. 2020R1A2C1014133), Korea.

Institutional Review Board Statement: Not applicable.

Informed Consent Statement: Not applicable.

Data Availability Statement: The data that support the results of this study will be provided from the corresponding author upon reasonable request.

Acknowledgments: Authors thank Ali Asjad for the first selection of OsCBE1 lines. This research was funded by the Next-Generation BioGreen 21 Program (PJ013295), Rural Development Administration, and the National Research Foundation (No. 2020R1A2C1014133), Korea.

Conflicts of Interest: The authors declare no conflict of interest and the funders had no role in the design of the study; in the collection, analyses, or interpretation of data; in the writing of the manuscript; or in the decision to publish the results.

\section{References}

1. Van Velthuizen, H. Mapping Biophysical Factors that Influence Agricultural Production and Rural Vulnerability; Food \& Agriculture Organization: Rome, Italy, 2007.

2. Ashraf, M.; Ahmad, M.S.A.; Öztürk, M.; Aksoy, A. Crop improvement through different means: Challenges and prospects. In Crop Production for Agricultural Improvement; Springer: Berlin, Germany, 2012; pp. 1-15.

3. Corlett, R.T.; Westcott, D.A. Will plant movements keep up with climate change? Trends Ecol. Evol. 2013, 28, 482-488. [CrossRef]

4. Zhu, J.-K. Abiotic stress signaling and responses in plants. Cell 2016, 167, 313-324. [CrossRef]

5. Yuan, F.; Yang, H.; Xue, Y.; Kong, D.; Ye, R.; Li, C.; Zhang, J.; Theprungsirikul, L.; Shrift, T.; Krichilsky, B. OSCA1 mediates osmotic-stress-evoked Ca 2+ increases vital for osmosensing in Arabidopsis. Nature 2014, 514, 367. [CrossRef]

6. Ma, Y.; Dai, X.; Xu, Y.; Luo, W.; Zheng, X.; Zeng, D.; Pan, Y.; Lin, X.; Liu, H.; Zhang, D. COLD1 confers chilling tolerance in rice. Cell 2015, 160, 1209-1221. [CrossRef] [PubMed]

7. Park, S.-Y.; Fung, P.; Nishimura, N.; Jensen, D.R.; Fujii, H.; Zhao, Y.; Lumba, S.; Santiago, J.; Rodrigues, A.; Tsz-fung, F.C. Abscisic acid inhibits type 2C protein phosphatases via the PYR/PYL family of START proteins. Science 2009, 324, 1068-1071. [CrossRef] [PubMed]

8. Ma, Y.; Szostkiewicz, I.; Korte, A.; Moes, D.; Yang, Y.; Christmann, A.; Grill, E. Regulators of PP2C phosphatase activity function as abscisic acid sensors. Science 2009, 324, 1064-1068. [CrossRef] [PubMed]

9. Boudsocq, M.; Barbier-Brygoo, H.; Laurière, C. Identification of nine sucrose nonfermenting 1-related protein kinases 2 activated by hyperosmotic and saline stresses in Arabidopsis thaliana. J. Biol. Chem. 2004, 279, 41758-41766. [CrossRef]

10. Choi, H.-I.; Hong, J.-H.; Ha, J.-O.; Kang, J.-Y.; Kim, S.Y. ABFs, a family of ABA-responsive element binding factors. J. Biol. Chem. 2000, 275, 1723-1730. [CrossRef]

11. Abe, H.; Yamaguchi-Shinozaki, K.; Urao, T.; Iwasaki, T.; Hosokawa, D.; Shinozaki, K. Role of Arabidopsis MYC and MYB homologs in drought-and abscisic acid-regulated gene expression. Plant Cell 1997, 9, 1859-1868. 
12. Agarwal, P.K.; Agarwal, P.; Reddy, M.; Sopory, S.K. Role of DREB transcription factors in abiotic and biotic stress tolerance in plants. Plant Cell Rep. 2006, 25, 1263-1274. [CrossRef]

13. Nakashima, K.; Takasaki, H.; Mizoi, J.; Shinozaki, K.; Yamaguchi-Shinozaki, K. NAC transcription factors in plant abiotic stress responses. Biochim. Biophys. Acta BBA Gene Regul. Mech. 2012, 1819, 97-103. [CrossRef]

14. Dubouzet, J.G.; Sakuma, Y.; Ito, Y.; Kasuga, M.; Dubouzet, E.G.; Miura, S.; Seki, M.; Shinozaki, K.; Yamaguchi-Shinozaki, K. OsDREB genes in rice, Oryza sativa L., encode transcription activators that function in drought-, high-salt-and cold-responsive gene expression. Plant J. 2003, 33, 751-763. [CrossRef] [PubMed]

15. Gilmour, S.J.; Sebolt, A.M.; Salazar, M.P.; Everard, J.D.; Thomashow, M.F. Overexpression of the Arabidopsis CBF3transcriptional activator mimics multiple biochemical changes associated with cold acclimation. Plant Phys. 2000, 124, 1854-1865. [CrossRef] [PubMed]

16. Liao, Y.; Zou, H.-F.; Wang, H.-W.; Zhang, W.-K.; Ma, B.; Zhang, J.-S.; Chen, S.-Y. Soybean GmMYB76, GmMYB92, and GmMYB177 genes confer stress tolerance in transgenic Arabidopsis plants. Cell Res. 2008, 18, 1047. [CrossRef] [PubMed]

17. Wu, X.; Gong, F.; Cao, D.; Hu, X.; Wang, W. Advances in crop proteomics: PTMs of proteins under abiotic stress. Proteomics 2016, 16, 847-865. [CrossRef] [PubMed]

18. Komander, D.; Rape, M. The ubiquitin code. Annu. Rev. Biochem. 2012, 81, 203-229. [CrossRef] [PubMed]

19. Ohtake, F.; Tsuchiya, H. The emerging complexity of ubiquitin architecture. J. Biochem. 2016, 161, 125-133. [CrossRef] [PubMed]

20. Kawahara, Y.; de la Bastide, M.; Hamilton, J.P.; Kanamori, H.; McCombie, W.R.; Ouyang, S.; Schwartz, D.C.; Tanaka, T.; Wu, J.; Zhou, S. Improvement of the Oryza sativa Nipponbare reference genome using next generation sequence and optical map data. Rice 2013, 6, 4. [CrossRef]

21. Lamesch, P.; Berardini, T.Z.; Li, D.; Swarbreck, D.; Wilks, C.; Sasidharan, R.; Muller, R.; Dreher, K.; Alexander, D.L.; GarciaHernandez, M. The Arabidopsis Information Resource (TAIR): Improved gene annotation and new tools. Nucleic Acids Res. 2011, 40, D1202-D1210. [CrossRef]

22. Du, Z.; Zhou, X.; Li, L.; Su, Z. PlantsUPS: A database of plants' Ubiquitin Proteasome System. BMC Gen. 2009, 10, 227. [CrossRef]

23. Lee, J.-H.; Terzaghi, W.; Gusmaroli, G.; Charron, J.-B.F.; Yoon, H.-J.; Chen, H.; He, Y.J.; Xiong, Y.; Deng, X.W. Characterization of Arabidopsis and rice DWD proteins and their roles as substrate receptors for CUL4-RING E3 ubiquitin ligases. Plant Cell 2008, 20, 152-167. [CrossRef]

24. Smalle, J.; Vierstra, R.D. The ubiquitin 26S proteasome proteolytic pathway. Annu. Rev. Plant Biol. 2004, 55, 555-590. [CrossRef]

25. Gray, W.M.; del Pozo, J.C.; Walker, L.; Hobbie, L.; Risseeuw, E.; Banks, T.; Crosby, W.L.; Yang, M.; Ma, H.; Estelle, M. Identification of an SCF ubiquitin-ligase complex required for auxin response in Arabidopsis thaliana. Gen. Dev. 1999, 13, 1678-1691. [CrossRef] [PubMed]

26. Marrocco, K.; Thomann, A.; Parmentier, Y.; Genschik, P.; Criqui, M.C. The APC/C E3 ligase remains active in most post-mitotic Arabidopsis cells and is required for proper vasculature development and organization. Development 2009, 136, 1475-1485. [CrossRef] [PubMed]

27. Figueroa, P.; Gusmaroli, G.; Serino, G.; Habashi, J.; Ma, L.; Shen, Y.; Feng, S.; Bostick, M.; Callis, J.; Hellmann, H. Arabidopsis has two redundant Cullin3 proteins that are essential for embryo development and that interact with RBX1 and BTB proteins to form multisubunit E3 ubiquitin ligase complexes in vivo. Plant Cell 2005, 17, 1180-1195. [CrossRef] [PubMed]

28. Chen, H.; Shen, Y.; Tang, X.; Yu, L.; Wang, J.; Guo, L.; Zhang, Y.; Zhang, H.; Feng, S.; Strickland, E. Arabidopsis CULLIN4 forms an E3 ubiquitin ligase with RBX1 and the CDD complex in mediating light control of development. Plant Cell 2006, 18, 1991-2004. [CrossRef] [PubMed]

29. Zhang, Y.; Feng, S.; Chen, F.; Chen, H.; Wang, J.; McCall, C.; Xiong, Y.; Deng, X.W. Arabidopsis DDB1-CUL4 ASSOCIATED FACTOR1 forms a nuclear E3 ubiquitin ligase with DDB1 and CUL4 that is involved in multiple plant developmental processes. Plant Cell 2008, 20, 1437-1455. [CrossRef] [PubMed]

30. Chen, H.; Huang, X.; Gusmaroli, G.; Terzaghi, W.; Lau, O.S.; Yanagawa, Y.; Zhang, Y.; Li, J.; Lee, J.-H.; Zhu, D. Arabidopsis CULLIN4-damaged DNA binding protein 1 interacts with constitutively photomorphogenic1-suppressor of phya complexes to regulate photomorphogenesis and flowering time. Plant Cell 2010, 22, 108-123. [CrossRef] [PubMed]

31. Maeda, K.; Houjyou, Y.; Komatsu, T.; Hori, H.; Kodaira, T.; Ishikawa, A. AGB1 and PMR5 contribute to PEN2-mediated preinvasion resistance to Magnaporthe oryzae in Arabidopsis thaliana. Mol. Plant-Microbe Interact. 2009, 22, 1331-1340. [CrossRef]

32. Lee, J.-H.; Yoon, H.-J.; Terzaghi, W.; Martinez, C.; Dai, M.; Li, J.; Byun, M.-O.; Deng, X.W. DWA1 and DWA2, two Arabidopsis DWD protein components of CUL4-based E3 ligases, act together as negative regulators in ABA signal transduction. Plant Cell 2010, 22, 1716-1732. [CrossRef]

33. Lee, J.; Zhou, P. DCAFs, the missing link of the CUL4-DDB1 ubiquitin ligase. Mol. Cell 2007, 26, 775-780. [CrossRef]

34. Biedermann, S.; Hellmann, H. WD40 and CUL4-based E3 ligases: Lubricating all aspects of life. Trends Plant Sci. 2011, 16, 38-46. [CrossRef] [PubMed]

35. Marchler-Bauer, A.; Bo, Y.; Han, L.; He, J.; Lanczycki, C.J.; Lu, S.; Chitsaz, F.; Derbyshire, M.K.; Geer, R.C.; Gonzales, N.R. CDD/SPARCLE: Functional classification of proteins via subfamily domain architectures. Nucleic Acids Res. 2016, 45, D200-D203. [CrossRef]

36. Kim, D.E.; Chivian, D.; Baker, D. Protein structure prediction and analysis using the Robetta server. Nucleic Acids Res. 2004, 32, W526-W531. [CrossRef] [PubMed] 
37. Szklarczyk, D.; Franceschini, A.; Wyder, S.; Forslund, K.; Heller, D.; Huerta-Cepas, J.; Simonovic, M.; Roth, A.; Santos, A.; Tsafou, K.P. STRING v10: Protein-protein interaction networks, integrated over the tree of life. Nucleic Acids Res. 2014, 43, D447-D452. [CrossRef]

38. Lyskov, S.; Chou, F.-C.; Conchúir, S.Ó.; Der, B.S.; Drew, K.; Kuroda, D.; Xu, J.; Weitzner, B.D.; Renfrew, P.D.; Sripakdeevong, P. Serverification of molecular modeling applications: The Rosetta Online Server that Includes Everyone (ROSIE). PLoS ONE 2013, 8, e63906. [CrossRef]

39. Kelley, L.A.; Mezulis, S.; Yates, C.M.; Wass, M.N.; Sternberg, M.J. The Phyre2 web portal for protein modeling, prediction and analysis. Nat. Protoc. 2015, 10, 845. [CrossRef]

40. Seok, H.-Y.; Nguyen, L.V.; Park, H.-Y.; Tarte, V.N.; Ha, J.; Lee, S.-Y.; Moon, Y.-H. Arabidopsis non-TZF gene AtC3H17 functions as a positive regulator in salt stress response. Biochem. Biophys. Res. Commun. 2018, 498, 954-959. [CrossRef] [PubMed]

41. Seok, H.-Y.; Woo, D.-H.; Park, H.-Y.; Lee, S.-Y.; Tran, H.T.; Lee, E.-H.; Vu Nguyen, L.; Moon, Y.-H. AtC3H17, a non-tandem $\mathrm{CCCH}$ zinc finger protein, functions as a nuclear transcriptional activator and has pleiotropic effects on vegetative development, flowering and seed development in Arabidopsis. Plant Cell Physiol. 2016, 57, 603-615. [CrossRef]

42. Seo, K.-I.; Lee, J.-H.; Nezames, C.D.; Zhong, S.; Song, E.; Byun, M.-O.; Deng, X.W. ABD1 is an Arabidopsis DCAF substrate receptor for CUL4-DDB1-based E3 ligases that acts as a negative regulator of abscisic acid signaling. Plant Cell 2014, 26, 695-711. [CrossRef]

43. Dutilleul, C.; Ribeiro, I.; Blanc, N.; Nezames, C.D.; Deng, X.W.; Zglobicki, P.; Palacio Barrera, A.M.; Atehortùa, L.; Courtois, M.; Labas, V. ASG2 is a farnesylated DWD protein that acts as ABA negative regulator in Arabidopsis. Plant Cell Environ. 2016, 39, 185-198. [CrossRef]

44. Irigoyen, M.L.; Iniesto, E.; Rodriguez, L.; Puga, M.I.; Yanagawa, Y.; Pick, E.; Strickland, E.; Paz-Ares, J.; Wei, N.; De Jaeger, G. Targeted degradation of abscisic acid receptors is mediated by the ubiquitin ligase substrate adaptor DDA1 in Arabidopsis. Plant Cell 2014, 26, 712-728. [CrossRef]

45. Fernando, V.D.; Schroeder, D.F. Arabidopsis DDB1-CUL4 E3 ligase complexes in det1 salt/osmotic stress resistant germination. Plant Signal. Behav. 2016, 11, e1223004. [CrossRef]

46. Lee, I.; Ambaru, B.; Thakkar, P.; Marcotte, E.M.; Rhee, S.Y. Rational association of genes with traits using a genome-scale gene network for Arabidopsis thaliana. Nat. Biotechnol. 2010, 28, 149. [CrossRef]

47. Lee, J.-H.; Terzaghi, W.; Deng, X.W. DWA3, an Arabidopsis DWD protein, acts as a negative regulator in ABA signal transduction. Plant Sci. 2011, 180, 352-357. [CrossRef]

48. Ali, A.; Yun, D.-J. Arabidopsis HOS15 is a multifunctional protein that negatively regulate ABA-signaling and drought stress. Plant Biotechnol. Rep. 2020, 14, 1-5. [CrossRef]

49. Li, D.; Zhang, L.; Li, X.; Kong, X.; Wang, X.; Li, Y.; Liu, Z.; Wang, J.; Li, X.; Yang, Y. AtRAE1 is involved in degradation of ABA receptor RCAR1 and negatively regulates ABA signalling in Arabidopsis. Plant Cell Environ. 2018, 41, 231-244. [CrossRef] [PubMed]

50. Park, S.-R.; Hwang, J.; Kim, M. The Arabidopsis WDR55 is positively involved in ABA-mediated drought tolerance response. Plant Biotechnol. Rep. 2020, 14, 407-418. [CrossRef]

51. Bae, Y.; Kim, H.; Kim, S.-H.; Lee, J.-H. Expression study on the Scaffold gene of CRL4 complex in rice (Oryza sativa L.). J. Life Sci. 2018, 28, 1132-1139.

52. Shabek, N.; Ruble, J.; Waston, C.J.; Garbutt, K.C.; Hinds, T.R.; Li, T.; Zheng, N. Structural insights into DDA1 function as a core component of the CRL4-DDB1 ubiquitin ligase. Cell Discov. 2018, 4, 1-4. [CrossRef] [PubMed]

53. Seo, J.S.; Zhao, P.; Jung, C.; Chua, N.-H. PLANT U-BOX PROTEIN 10 negatively regulates abscisic acid response in Arabidopsis. Appl. Biol. Chem. 2019, 62, 39. [CrossRef]

54. Wang, N.; Liu, Y.; Cai, Y.; Tang, J.; Li, Y.; Gai, J. The soybean U-box gene GmPUB6 regulates drought tolerance in Arabidopsis thaliana. Plant Physiol. Biochem. 2020, 155, 284-296. [CrossRef] [PubMed]

55. Wang, N.; Liu, Y.; Cong, Y.; Wang, T.; Zhong, X.; Yang, S.; Li, Y.; Gai, J. Genome-wide identification of soybean U-box E3 ubiquitin ligases and roles of GmPUB8 in negative regulation of drought stress response in Arabidopsis. Plant Cell Physiol. 2016, 57, 1189-1209. [CrossRef] [PubMed]

56. Cho, S.K.; Ryu, M.Y.; Kim, J.H.; Hong, J.S.; Oh, T.R.; Kim, W.T.; Yang, S.W. RING E3 ligases: Key regulatory elements are involved in abiotic stress responses in plants. BMB Rep. 2017, 50, 393. [CrossRef] [PubMed]

57. Zhang, M.; Zhao, J.; Li, L.; Gao, Y.; Zhao, L.; Patil, S.B.; Fang, J.; Zhang, W.; Yang, Y.; Li, M. The Arabidopsis U-box E3 ubiquitin ligase PUB30 negatively regulates salt tolerance by facilitating BRI1 kinase inhibitor 1 (BKI1) degradation. Plant Cell Environ. 2017, 40, 2831-2843. [CrossRef] [PubMed]

58. Zhao, J.; Zhao, L.; Zhang, M.; Zafar, S.A.; Fang, J.; Li, M.; Zhang, W.; Li, X. Arabidopsis E3 ubiquitin ligases PUB22 and PUB23 negatively regulate drought tolerance by targeting ABA receptor PYL9 for degradation. Int. J. Mol. Sci. 2017, 18, 1841. [CrossRef]

59. Seo, D.H.; Ahn, M.Y.; Park, K.Y.; Kim, E.Y.; Kim, W.T. The N-terminal UND motif of the Arabidopsis U-box E3 ligase PUB18 is critical for the negative regulation of ABA-mediated stomatal movement and determines its ubiquitination specificity for exocyst subunit Exo70B1. Plant Cell 2016, 28, 2952-2973. [CrossRef]

60. Seo, D.H.; Ryu, M.Y.; Jammes, F.; Hwang, J.H.; Turek, M.; Kang, B.G.; Kwak, J.M.; Kim, W.T. Roles of four Arabidopsis U-box E3 ubiquitin ligases in negative regulation of abscisic acid-mediated drought stress responses. Plant Physiol. 2012, 160, 556-568. [CrossRef] [PubMed] 
61. Makino, A. Photosynthesis, grain yield, and nitrogen utilization in rice and wheat. Plant Physiol. 2011, 155, 125-129. [CrossRef]

62. Yoshida, S. Fundamentals of Rice Crop Science; The International Rice Research Institute: Los Baños, Philippines, 1981.

63. Yoshida, H.; Horie, T.; Shiraiwa, T. A model explaining genotypic and environmental variation of rice spikelet number per unit area measured by cross-locational experiments in Asia. Field Crops Res. 2006, 97, 337-343. [CrossRef]

64. Kim, H.; Lee, K.; Hwang, H.; Bhatnagar, N.; Kim, D.-Y.; Yoon, I.S.; Byun, M.-O.; Kim, S.T.; Jung, K.-H.; Kim, B.-G. Overexpression of PYL5 in rice enhances drought tolerance, inhibits growth, and modulates gene expression. J. Exp. Bot. 2014, 65, 453-464. [CrossRef] [PubMed]

65. Miao, C.; Xiao, L.; Hua, K.; Zou, C.; Zhao, Y.; Bressan, R.A.; Zhu, J.-K. Mutations in a subfamily of abscisic acid receptor genes promote rice growth and productivity. Proc. Natl. Acad. Sci. USA 2018, 115, 6058-6063. [CrossRef]

66. Benanti, J.A.; Cheung, S.K.; Brady, M.C.; Toczyski, D.P. A proteomic screen reveals SCF Grr1 targets that regulate the glycolyticgluconeogenic switch. Nat. Cell Biol. 2007, 9, 1184. [CrossRef] [PubMed]

67. Guo, Z.; Wang, X.; Li, H.; Gao, Y. Screening E3 substrates using a live phage display library. PLoS ONE 2013, 8, e76622. [CrossRef] [PubMed]

68. Yen, H.-C.S.; Xu, Q.; Chou, D.M.; Zhao, Z.; Elledge, S.J. Global protein stability profiling in mammalian cells. Science 2008, 322, 918-923. [CrossRef]

69. Kim, T.Y.; Siesser, P.F.; Rossman, K.L.; Goldfarb, D.; Mackinnon, K.; Yan, F.; Yi, X.; MacCoss, M.J.; Moon, R.T.; Der, C.J. Substrate trapping proteomics reveals targets of the $\beta$ TrCP2/FBXW11 ubiquitin ligase. Mol. Cell. Biol. 2015, 35, 167-181. [CrossRef]

70. Lee, K.A.; Hammerle, L.P.; Andrews, P.S.; Stokes, M.P.; Mustelin, T.; Silva, J.C.; Black, R.A.; Doedens, J.R. Ubiquitin ligase substrate identification through quantitative proteomics at both the protein and peptide levels. J. Biol. Chem. 2011, 286, 41530-41538. [CrossRef]

71. Andrews, P.S.; Schneider, S.; Yang, E.; Michaels, M.; Chen, H.; Tang, J.; Emkey, R. Identification of substrates of SMURF1 ubiquitin ligase activity utilizing protein microarrays. Assay Drug Dev. Technol. 2010, 8, 471-487. [CrossRef]

72. Maier, A.; Schrader, A.; Kokkelink, L.; Falke, C.; Welter, B.; Iniesto, E.; Rubio, V.; Uhrig, J.F.; Hülskamp, M.; Hoecker, U. Light and the E3 ubiquitin ligase COP 1/SPA control the protein stability of the MYB transcription factors PAP 1 and PAP 2 involved in anthocyanin accumulation in Arabidopsis. Plant J. 2013, 74, 638-651. [CrossRef] [PubMed]

73. Iconomou, M.; Saunders, D.N. Systematic approaches to identify E3 ligase substrates. Biochem. J. 2016, 473, 4083-4101. [CrossRef]

74. Li, Y.; Xie, P.; Lu, L.; Wang, J.; Diao, L.; Liu, Z.; Guo, F.; He, Y.; Liu, Y.; Huang, Q. An integrated bioinformatics platform for investigating the human E3 ubiquitin ligase-substrate interaction network. Nat. Commun. 2017, 8, 1-9. [CrossRef] [PubMed]

75. Sato, Y.; Takehisa, H.; Kamatsuki, K.; Minami, H.; Namiki, N.; Ikawa, H.; Ohyanagi, H.; Sugimoto, K.; Antonio, B.A.; Nagamura, Y. RiceXPro version 3.0: Expanding the informatics resource for rice transcriptome. Nucleic Acids Res. 2013, 41, D1206-D1213. [CrossRef] [PubMed]

76. Nie, X.-F.; Maclean, K.N.; Kumar, V.; McKay, I.A.; Bustin, S.A. ERF-2, the human homologue of the murine Tis11d early response gene. Gene 1995, 152, 285-286. [CrossRef]

77. Mello, C.C.; Schubert, C.; Draper, B.; Zhang, W.; Lobel, R.; Priess, J.R. The PIE-1 protein and germline specification in C. elegans embryos. Nature 1996, 382, 710-712. [CrossRef]

78. Ma, Q.; Wadleigh, D.; Chi, T.; Herschman, H. The Drosophila TIS11 homologue encodes a developmentally controlled gene. Oncogene 1994, 9, 3329-3334. [PubMed]

79. Thompson, M.J.; Lai, W.S.; Taylor, G.A.; Blackshear, P.J. Cloning and characterization of two yeast genes encoding members of the $\mathrm{CCCH}$ class of zinc finger proteins: Zinc finger-mediated impairment of cell growth. Gene 1996, 174, 225-233. [CrossRef]

80. Wang, D.; Guo, Y.; Wu, C.; Yang, G.; Li, Y.; Zheng, C. Genome-wide analysis of CCCH zinc finger family in Arabidopsis and rice. BMC Genom. 2008, 9, 44. [CrossRef]

81. Peng, X.; Zhao, Y.; Cao, J.; Zhang, W.; Jiang, H.; Li, X.; Ma, Q.; Zhu, S.; Cheng, B. CCCH-type zinc finger family in maize: Genome-wide identification, classification and expression profiling under abscisic acid and drought treatments. PLoS ONE 2012, 7, e40120. [CrossRef]

82. Pi, B.; He, X.; Ruan, Y.; Jang, J.-C.; Huang, Y. Genome-wide analysis and stress-responsive expression of CCCH zinc finger family genes in Brassica rapa. BMC Plant Biol. 2018, 18, 1-15. [CrossRef]

83. Wang, W.; Liu, B.; Xu, M.; Jamil, M.; Wang, G. ABA-induced CCCH tandem zinc finger protein OsC3H47 decreases ABA sensitivity and promotes drought tolerance in Oryza sativa. Biochem. Biophys. Res. Commun. 2015, 464, 33-37. [CrossRef]

84. Kumar, M.; Choi, J.; An, G.; Kim, S.-R. Ectopic expression of OsSta2 enhances salt stress tolerance in rice. Front. Plant Sci. 2017, 8, 316. [CrossRef] [PubMed]

85. Kim, S.-H.; Choi, H.-S.; Cho, Y.-C.; Kim, S.-R. Cold-responsive regulation of a flower-preferential class III peroxidase gene, OsPOX1, in rice (Oryza sativa L.). J. Plants Biol. 2012, 55, 123-131. [CrossRef]

86. Lee, S.-C.; Kim, S.-H.; Kim, S.-R. Drought inducible OsDhn1 promoter is activated by OsDREB1A and OsDREB1D. J. Plants Biol. 2013, 56, 115-121. [CrossRef]

87. Ni, Z.; Kim, E.-D.; Chen, Z.J. Chlorophyll and starch assays. Protoc. Exch. 2009, 10, 1038. [CrossRef]

88. Chen, D.-H.; Ronald, P. A rapid DNA minipreparation method suitable for AFLP and other PCR applications. Plant. Mol. Biol. Rep. 1999, 17, 53-57. [CrossRef] 
89. Koh, S.; Lee, S.-C.; Kim, M.-K.; Koh, J.H.; Lee, S.; An, G.; Choe, S.; Kim, S.-R. T-DNA tagged knockout mutation of rice OsGSK1, an orthologue of Arabidopsis BIN2, with enhanced tolerance to various abiotic stresses. Plant. Mol. Biol. 2007, 65, 453-466. [CrossRef]

90. Schneider, C.A.; Rasband, W.S.; Eliceiri, K.W. NIH Image to ImageJ: 25 years of image analysis. Nat. Methods 2012, 9, 671-675. [CrossRef]

91. Kim, S.-R.; Lee, D.-Y.; Yang, J.-I.; Moon, S.; An, G. Cloning vectors for rice. J. Plants Biol. 2009, 52, 73. [CrossRef]

92. Yoon, J.; Cho, L.-H.; Antt, H.W.; Koh, H.-J.; An, G. KNOX protein OSH15 induces grain shattering by repressing lignin biosynthesis genes. Plants Physiol. 2017, 174, 312-325. [CrossRef]

93. Liu, C.; Mao, B.; Ou, S.; Wang, W.; Liu, L.; Wu, Y.; Chu, C.; Wang, X. OsbZIP71, a bZIP transcription factor, confers salinity and drought tolerance in rice. Plants Mol. Biol. 2014, 84, 19-36. [CrossRef]

94. Schenkelberg, C.D.; Bystroff, C. InteractiveROSETTA: A graphical user interface for the PyRosetta protein modeling suite. Bioinformatics 2015, 31, 4023-4025. [CrossRef] [PubMed]

95. Leaver-Fay, A.; Tyka, M.; Lewis, S.M.; Lange, O.F.; Thompson, J.; Jacak, R.; Kaufman, K.W.; Renfrew, P.D.; Smith, C.A.; Sheffler, W. ROSETTA3: An object-oriented software suite for the simulation and design of macromolecules. In Methods in Enzymology; Elsevier: Amsterdam, The Netherlands, 2011; Volume 487, pp. 545-574.

96. Basu, S.; Wallner, B. DockQ: A quality measure for protein-protein docking models. PLoS ONE 2016, 11, e0161879. [CrossRef]

97. Pierce, B.G.; Wiehe, K.; Hwang, H.; Kim, B.-H.; Vreven, T.; Weng, Z. ZDOCK server: Interactive docking prediction of proteinprotein complexes and symmetric multimers. Bioinformatics 2014, 30, 1771-1773. [CrossRef] [PubMed]

98. Schrodinger, L.L.C. The PyMOL Molecular Graphics System, Version 1.8; Schrodinger, L.L.C.: New York, NY, USA, 2015.

99. Cho, L.-H.; Yoon, J.; Pasriga, R.; An, G. Homodimerization of Ehd1 is required to induce flowering in rice. Plants Physiol. 2016, 170, 2159-2171. [CrossRef] [PubMed]

100. Ryu, C.H.; Lee, S.; Cho, L.H.; Kim, S.L.; Lee, Y.S.; Choi, S.C.; Jeong, H.J.; Yi, J.; Park, S.J.; Han, C.D. OsMADS50 and OsMADS56 function antagonistically in regulating long day (LD)-dependent flowering in rice. Plants Cell Environ. 2009, 32, 1412-1427. [CrossRef] [PubMed] 